WellBeing International

WBI Studies Repository

10-2008

\title{
When to be a Dear Enemy: Flexible Acoustic Relationships of Neighbouring Skylarks, Alauda arvensis
}

\author{
Elodie Briefer \\ University of Paris-Sud \\ Fanny Rybak \\ University of Paris-Sud \\ Thierry Aubin \\ University of Paris-Sud
}

Follow this and additional works at: https://www.wellbeingintlstudiesrepository.org/acwp_ena

Part of the Animal Studies Commons, Behavior and Ethology Commons, and the Comparative Psychology Commons

\section{Recommended Citation}

Briefer, E., Rybak, F., \& Aubin, T. (2008). When to be a dear enemy: flexible acoustic relationships of neighbouring skylarks, Alauda arvensis. Animal Behaviour, 76(4), 1319-1325.

This material is brought to you for free and open access by WellBeing International. It has been accepted for inclusion by an authorized administrator of the WBI Studies Repository. For more information, please contact wbisr-info@wellbeingintl.org.

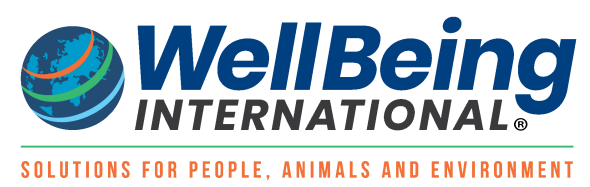




\title{
When to be a Dear Enemy: Flexible Acoustic Relationships of Neighbouring Skylarks, Alauda arvensis
}

\author{
Elodie Briefer, Fanny Rybak, and Thierry Aubin \\ University of Paris
}

\section{$\underline{\text { KEYWORDS }}$}

Alauda arvensis, dear enemy relationships, oscine, playback experiment, skylark

\section{$\underline{\text { ABSTRACT }}$}

Numerous territorial species are less aggressive towards neighbours than strangers. This tolerance towards neighbouring conspecifics, termed the 'dear enemy' effect, seems to be a flexible feature of the relationship between neighbours, and has been shown to disappear in some species after experimental or natural modifications of the context. However, the maintenance over time of this singular relationship has been poorly studied. In this study, we followed the change of dear enemy relationships during the breeding season in a territorial songbird with a complex song, the skylark. We examined in the field the response of territory owners to playbacks of neighbour and stranger songs at three periods of the breeding season, corresponding to three ecological and social situations. Results showed that neighbours were dear enemies in the middle of the season, when territories were stable, but not at the beginning of the breeding season, during settlement and pair formation, nor at the end, when bird density increased owing to the presence of young birds becoming independent. Thus, the dear enemy relationship is not a fixed pattern but a flexible one likely to evolve with social and ecological circumstances.

The 'dear enemy phenomenon' was first defined by Fisher (1954) to explain neighbor--stranger interactions characterized by reduced aggression from territory owners towards familiar individuals established in neighbouring territories compared to unfamiliar individuals. Residents respond less strongly to the intrusion of familiar or trusted individuals than to strangers (individuals with whom previous encounters with residents are unlikely because their territories are too distant) or floaters (Temeles 1994). Such a phenomenon has been observed in numerous territorial species, including songbirds (e.g. Brindley 1991), non-songbirds (e.g. suboscines, Lovell \& Lein 2004; Falls \& McNicholl 1979), mammals (e.g. Randall 1984), lizards (e.g. Husak \& Fox 2003), amphibians (e.g. Bee \& Gerhardt 2001a), fish (Leiser \& Itzkowitz 1999) and insects (Pfennig \& Reeve 1989). The function of the dear enemy effect could be to minimize the energy expended on aggressive acts or to prevent escalated conflicts between neighbours. Adjoining neighbours can thus use these time and energy savings for other aspects of their time budget such as attracting mates or tending to young (Ydenberg et al. 1988; Temeles 1994). 
The hypothetical bases for such neighbourhood relationships are the familiarity existing between individuals and the relative threat posed by different categories of individuals. As neighbouring territory owners become more familiar, role mistakes become less likely and the intensity of aggression between them decreases ('asymmetric war-of-attrition', Ydenberg et al. 1988). Furthermore, as postulated by Temeles (1994), residents may lose both their territory and their mate because of interactions with strangers whereas they may lose only their mate from interactions with neighbours already in possession of a suitable territory. As a consequence, residents respond more aggressively to strangers that constitute a more serious threat than to neighbours. Conversely, in species with high territorial instability, males, females or both sexes do not respond differently to neighbours versus strangers (e.g. strawberry dart-poison frog, Dendrobates pumilio: Bee 2003; rail, Gallirallus philippensis: Lachish \& Goldizen 2004). Furthermore, the reverse phenomenon in which individuals react more strongly to conspecific neighbouring colonies or groups than to distant ones has also been observed. Being 'nasty neighbours' instead of 'dear enemies' seems to be the rule in social insect, mammal or bird species with intense competition between neighbours (e.g. northern harrier, Circus cyaneus: Temeles 1990; the termite Nasutitermes corniger: Dunn \& Messier 1999; the ant Pristomyrmex pungens: Morimura et al. 2003; banded mongoose, Mungos mungo; Müller \& Manser 2007).

As inferred from the theoretical bases, territorial response to neighbours has been shown to depend on their level of aggressiveness (Hyman \& Hughes 2006). Consequently dear enemy relationships may be influenced by changes in the social situation or in the competitor's condition, motivation or intention. For instance, during increased flux in boundaries, caused either by the appearance of a vacant area between two territories (song sparrows, Melospiza melodia: Stoddard et al. 1990, 1991) or by the arrival of new birds claiming territories (Carolina wren, Thryothorus ludovicianus: Hyman 2005), neighbours and strangers seem to constitute equal rivals for residents. In the same way, males were more aggressive to their neighbours during and after playback simulations of neighbour aggression (Stoddard et al. 1991; Godard 1993; Naguib \& Todt 1998). Hence, accepting neighbours as dear enemies is a Tit-for-Tat conditional strategy which ends if neighbours fail to respect mutual territorial boundaries (Trivers 1971; Axelrod \& Hamilton 1981) and which is stabilized in part by retaliation against cheaters (Molles \& Vehrencamp 2001; Olendorf et al. 2003).

The conditional tolerance between dear enemies is thus expected to be a dynamic process. In this study, using an experimental approach, we characterized the establishment of dear enemy relationships of a territorial songbird and followed the interactions between neighbours throughout the breeding season. The skylark settles in pairs in adjacent territories in open landscape during the breeding season, from February to the end of July (Delius 1963). Owing to the heterogeneity of the habitat, territories are concentrated in particular locations and individuals are thus gathered in distinct small groups of 'neighbours' spaced by a few kilometres from 'strangers'. Skylarks show strong site fidelity within and between breeding seasons. Thus, both males and females have a strong tendency to return to the same breeding location from year to year (Jenny 1990). Throughout the breeding season, males defend multipurpose territories and are fiercely territorial (Donald 2004). On their territories, they display a wellmarked behaviour by flying towards intruders, making threat postures or even fighting. As in other oscine species, song production is part of the territorial behaviour: each male produces one of the most complex songs among oscines consisting of more than 300 different sound units (Aubin 1981). Linked to the spatial distribution of the males, microgeographical variation exists in songs and constitutes a group signature used by residents for discriminating neighbours from strangers (Briefer et al. 2008). However, these neighbours are likely to be unfamiliar individuals at the time of their first encounter when arriving in the breeding area to settle on territories. We thus explored when, in natural conditions, dear enemy relationships were seen and whether they persisted throughout the breeding season. 
To this end, we carried out playback experiments with stranger and neighbour songs at three periods of the breeding season: at the beginning during territory settlement and pair formation, in the middle when territories were well established, and at the end when young birds of the first clutch became independent and began to fly. We predicted that the dynamic process of establishment and maintenance of a dear enemy relationship would be influenced by familiarization with the acoustic cues necessary for neighbour identification and by the relative threat presented by neighbours compared with strangers, as potential usurpers of territories and mates, throughout the breeding season.

\section{METHODS}

\section{Study Area, Subjects and Song Recordings}

The experiment was conducted during the two breeding seasons of 2006 and 2007, from February to June, in the fields surrounding the University of Paris 11, France. A total of 23 males were tested. Thirteen males were tested twice during the same breeding season, at the beginning and in the middle (five males from two locations in 2006 and eight males from four additional locations in 2007), and 10 different males from three additional locations were tested only at the end of the season in 2007, corresponding to two to four males tested per location. We did not test the same birds three times to prevent habituation, which appears after a few signal presentations and persists for life (Aubin 1981, 1982). At one location, males were established in adjoining and stable territories and we refer to them as 'neighbours'. The mean number of neighbours (group size) within each of the nine locations of our study \pm SE was $8.25 \pm 0.80$ (range 5-12). We refer to males from two different locations situated at least $2 \mathrm{~km}$ apart as 'strangers' (Briefer et al. 2008). We could not ring the birds because skylarks are extremely difficult to catch during the breeding season, but, as site tenacity is very strong during this period (Delius 1965), we could easily identify individuals by observing their position and movements, especially when they were performing flight songs. We estimated the boundaries of the studied territories after numerous and careful observations of the birds' movements at different times of the day. GPS coordinates (Garmin GPSMAP 76S, Garmin International Inc., Olathe, Karsas, U.S.A.) were recorded at the centre of each territory. At the beginning of the breeding season, boundaries between territories were more disputed and more intrusions were observed, but the spatial distribution of territories remained unchanged throughout the season. The territorial song is usually produced from mid-January until late July (Lange 1951; Delius 1965). We recorded several songs per individual at the beginning of the season, from the middle of February to the end of March, between 0900 and 1200 hours Eastern Daylight Time, using a Marantz PMD 690 digital recorder (sampling rate: $48000 \mathrm{~Hz}$ ) connected to a Sennheiser ME $64 \mathrm{~K} 6$ omnidirectional microphone (frequency response: $30 \mathrm{~Hz}$ to $20 \mathrm{kHz} \pm 1 \mathrm{~dB}$ ) mounted in a Telinga Universal parabola (diameter: $50 \mathrm{~cm}$ ). Song files were then transferred to a computer and high-pass filtered (cutoff frequency: $1600 \mathrm{~Hz}$ ) to remove the background noise. Avisoft SASLab pro version 4.31 software (Specht 2004) was used for the preparation of song playback stimuli.

\section{Signals Tested}

We broadcast two categories of songs to each subject tested: a familiar neighbour song $(\mathrm{N})$ and a stranger song (S). We selected songs from our recordings, and all the selected songs were adjusted to the same duration by taking the first $90 \mathrm{~s}$. Using Goldwave version 5.11 (Craig 2000), we rescaled each recorded song to match the root mean square (RMS) amplitude of the different songs at the same output level. For one given subject, the $\mathrm{N}$ song broadcast was a song produced by one of its adjacent neighbours, while the $\mathrm{S}$ song was a song produced by an individual established in a territory situated in the most distant location within the study site from the subject's one. To avoid pseudoreplication (McGregor et al. 1992), a different $\mathrm{N}$ song was prepared for each subject, and two or three different $\mathrm{S}$ songs were prepared for each location. 


\section{Playback Procedures}

We carried out three distinct sessions of playbacks. The first session was conducted during the period corresponding to the settlement, from the end of February to the middle of April (beginning of the season: period 1). The second session was conducted just after the hatching of the first clutch, in May (middle of the season: period 2; Delius 1963). The third session was conducted in June (end of the season: period 3), just after the hatching of the second clutch. Trials were carried out between 0900 and 1200 hours Eastern Daylight Time. Experimental songs were played back with a Marantz PMD 690 digital recorder connected via a $20 \mathrm{~m}$ cable to a 10W Megavox Pro mega-6000 loudspeaker (frequency response: 400 $\mathrm{Hz}-10 \mathrm{kHz} \pm 3 \mathrm{~dB})$, at the intensity estimated to be normal for the birds $(\bar{X} \pm \mathrm{SE} 1 / 4$ 90:8 \pm 0:8 dB sound pressure level measured at $1 \mathrm{~m}$ from the loudspeaker with a Brüel \& Kjaer 2235, linear setting). The loudspeaker was positioned on the ground at approximately $5 \mathrm{~m}$ inside the territory of the subject, on the side of the boundary shared with the neighbour whose song was used as a stimulus. The experimenter stood $20 \mathrm{~m}$ from the loudspeaker. One $\mathrm{N}$ song and one $\mathrm{S}$ song, separated by at least a 5 min delay, were broadcast on the same day to each subject in a random order of presentation. The playback was initiated when the subject was standing on the ground inside its territory at more than $10 \mathrm{~m}$ from the loudspeaker, just after it had been seen singing and when adjacent neighbours were quiet. To avoid habituation (Aubin 1982), each subject was tested only once per playback session with the two categories of songs. For each subject tested at both period 1 and period 2, the same $\mathrm{N}$ and $\mathrm{S}$ songs were broadcast from the same position following the same procedure in the two playback sessions. Thus, observed responses cannot be attributed to a difference between the songs played back at these two periods. The number of elapsed days between periods 1 and 2 differed between individuals ( $\bar{X} \pm$ SE $=45 \pm 5: 3$ days $N=13$ ).

\section{Measures of Response and Statistical Analysis}

For each trial, the response of the bird was scored by the observer during $180 \mathrm{~s}$, corresponding to the broadcast of $90 \mathrm{~s}$ of continuous song and $90 \mathrm{~s}$ of postplayback silence. Skylark males display a very strong territorial behaviour with stereotyped patterns, which are easy to observe (Delius 1963). A male reacts vigorously against territorial intrusion by flying towards the intruder and by landing in its vicinity or flying low over it. It then takes a fight posture, head and crest up, and utters threat calls. Thus, we chose to record 11 measures of response to assess the effects of the different categories of songs played back (Table 1).

We used principal components analysis (PCA) based on the correlation matrix to create a composite score with the measures of response scored during the $180 \mathrm{~s}$ of trial, which are likely to be correlated (McGregor 1992). The PCA was performed on the responses to $\mathrm{N}$ and S songs of subjects tested at both period 1 and period 2. The scores of the first principal component (PC1) were compared by using a twofactor repeated measures ANOVA, the first factor being the playback session (period 1 or 2) and the second being the category of song played back ( $N$ or $S$ ). Further post hoc comparisons were made with two-tailed Tukey honest significant difference (HSD) tests.

As the third playback session (period 3) was done with a different set of subjects to the first two sessions, the eigenvectors extracted from the PCA generated with the data from the first two sessions were applied to the data from the third session. The resulting scores from the first principal component (PC1) obtained for the playback of $\mathrm{S}$ and $\mathrm{N}$ songs were compared by using a $t$ test for dependent samples.

We compared PC1 scores obtained for each category of song played back at period 3 to PC1 scores obtained at periods 1 and 2 by using $t$ tests for independent samples. A sequential Bonferroni adjustment was applied to these comparisons and all results retained significance when $P<0.025$ (i.e. $0.05 / 2$ as two comparisons were made: period 1 versus period 3, period 2 versus period 3). 
The same comparisons were made with the scores of the second principal component (PC2). For all analyses we used Statistica version 6 (StatSoft Inc. 2001).

Table 1. Measures of response to playback

\begin{tabular}{|c|c|}
\hline Response category & Measured variable \\
\hline Movements (s) & $\begin{array}{l}\text { Total duration } \\
\text { Duration between } 10 \text { and } 5 \mathrm{~m} \text { from the loudspeaker } \\
\text { Duration between } 5 \text { and } 0 \mathrm{~m} \text { from the loudspeaker }\end{array}$ \\
\hline Latency (s) & $\begin{array}{l}\text { Before the first movement } \\
\text { To approach at less than } 10 \mathrm{~m} \text { from the loudspeaker } \\
\text { To approach at less than } 5 \mathrm{~m} \text { from the loudspeaker }\end{array}$ \\
\hline Time spent (s) & $\begin{array}{l}\text { Between } 10 \text { and } 5 \mathrm{~m} \text { from the loudspeaker } \\
\text { Between } 5 \text { and } 0 \mathrm{~m} \text { from the loudspeaker }\end{array}$ \\
\hline Vocalizations & $\begin{array}{l}\text { Latency before the first song }(\mathrm{s}) \\
\text { Duration of songs (s) } \\
\text { Total number of calls }\end{array}$ \\
\hline
\end{tabular}

\section{RESULTS}

Although the two categories of songs ( $\mathrm{N}$ and $\mathrm{S}$ ) were randomly broadcast to a given subject, we tested for each playback session the possibility of a confounding effect of habituation or increasing aggression caused by an order effect. A t test for dependent samples with the order of presentation of the playback treatments as repeated measures and the responses of subjects as the dependent variables revealed no order effect for any of the playback sessions (period 1: $t_{12}=-0.78, P=0.45$; period 2: $t_{12}=-0.53, P=$ 0.60 ; period 3: $t_{9}=1.15, P=0.28$ ).

The first principal component (PC1) explained 34.8\% of the variance in the responses measured. The durations of movements at different distances from the loudspeaker, the latencies to approach at less than $10 \mathrm{~m}$ and at less than $5 \mathrm{~m}$ from the loudspeaker and the time spent at less than $5 \mathrm{~m}$ from the loudspeaker were strongly correlated with PC1 compared to the other responses (Table 2). Higher positive values of PC1 corresponded to a stronger response, that is, subjects spent more time in movements, approached closer to the loudspeaker after a shorter latency and produced more calls. A comparison between PC1 scores obtained at period 1 and period 2 revealed a significant interaction effect of the test period (1 or 2) and the category of song played back ( $\mathrm{N}$ or $\mathrm{S}$ ) on the subject's responses (repeated measures ANOVA: $F_{1,12}=16.08 ; P<0.01$ ). Further post hoc comparisons revealed that subjects responded significantly more strongly to $\mathrm{S}$ songs than to $\mathrm{N}$ songs at period 2 (Tukey HSD test: $N$ $=13, P<0.01)$, but the difference was not significant at period $1(N=13, P=0.82 ;$ Fig. 1$)$. The responses of subjects to $N$ songs were stronger at period 1 than at period $2\left(N \frac{1}{4} 13, P<0.01\right.$; Figs. 1, 2), but the responses to $S$ songs were not significantly different between these two periods $(N=13, P=0.58$; Figs. 1, 2).

At period 3, a comparison between PC1 scores showed that subjects' responses to $\mathrm{S}$ and $\mathrm{N}$ songs were not significantly different (dependent samples $t$ test: $t_{9}=1.29 P=0.23$; Fig. 1).

Comparisons between the PC1 scores obtained at period 3 and the PC1 scores obtained at periods 1 and 2 showed that responses of subjects to $\mathrm{N}$ songs were stronger at period 3 than at period 2 (independent samples $t$ test: $t_{21}=-3.03, P<0.01$; Fig. 1 ), and that there was no significant difference in the responses of subjects to $\mathrm{N}$ songs between periods 1 and $3\left(t_{21}=0.83 ; P=0.42\right)$. The subjects did not 
respond significantly differently to $S$ songs between periods 1 and $3\left(t_{21}=0.92, P=0.37\right)$, and between periods 2 and $3\left(t_{21}=1.75, P=0.10\right)$.

Table 2. Eigenvalue, variance explained, and loadings of the measures of response on the first (PC1) and second (PC2) principal components for playbacks of neighbour and stranger songs at the beginning, in the middle and at the end of the breeding season

\begin{tabular}{|lcc|}
\hline Statistics and response measures & PC1 & PC2 \\
\hline Eigenvalue & 3.823 & 1.678 \\
Percentage of variance & 34.757 & 15.254 \\
Duration of movements between 5 and 0 $\mathrm{m}$ & $\mathbf{0 . 8 2 6}$ & -0.315 \\
Latency to approach at less than $5 \mathrm{~m}$ & $\mathbf{- 0 . 8 0 7}$ & 0.281 \\
Latency to approach at less than $10 \mathrm{~m}$ & $\mathbf{- 0 . 7 6 2}$ & 0.092 \\
Total duration of movements & $\mathbf{0 . 7 5 9}$ & 0.017 \\
Duration of movements between 10 and 5 m & $\mathbf{0 . 6 5 0}$ & 0.171 \\
Time spent between 5 and 0 $\mathrm{m}$ & $\mathbf{0 . 5 6 1}$ & -0.453 \\
Total number of calls & 0.466 & 0.086 \\
Duration of songs & -0.371 & $\mathbf{- 0 . 6 5 0}$ \\
Latency before the first song & 0.334 & $\mathbf{0 . 8 0 3}$ \\
Time spent between 10 and $5 \mathrm{~m}$ & 0.305 & 0.426 \\
Latency before the first movement & -0.191 & -0.044 \\
\hline
\end{tabular}

Measures that contributed most to the particular compound variables are in bold.

Figure 1. Mean \pm SE PC1 scores for playbacks of neighbour $(N)$ and stranger $(\mathrm{S})$ songs at the beginning and in the middle of the breeding season $(N=13)$, and at the end of the breeding season $(N=10) . * *<0.01$. Different letters indicate significant differences between scores for playbacks of $\mathrm{N}$ song (see text for statistics).

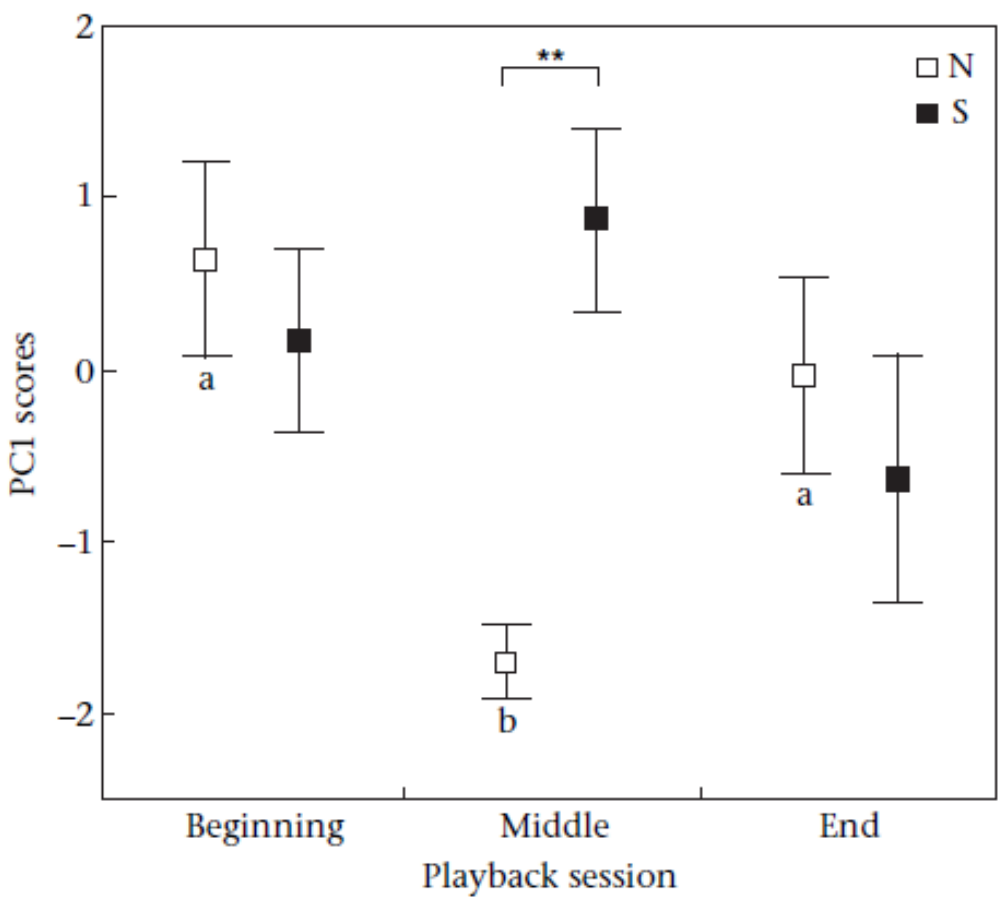


The second principal component (PC2) explained 15.3\% of the variance in the responses measured. The duration of songs and the latency before the first song were strongly correlated with PC2 compared to the other responses (Table 2). No significant effect of the broadcast of the two categories of songs on PC2 scores was found (periods 1 and 2: repeated measures ANOVA: $F_{1,12}=1.53, P=0.24$; period 3 : dependent samples $t$ test: $t_{9}=-0.29, P=0.78$ )

Figure 2. Individual PC1 scores $(N=13)$ for playbacks of (a) neighbor song and (b) stranger song at the beginning and in the middle of the breeding season. Individuals are identified by a number. Differences between the beginning and the middle for playbacks of neighbour song are significant (see text for statistics).

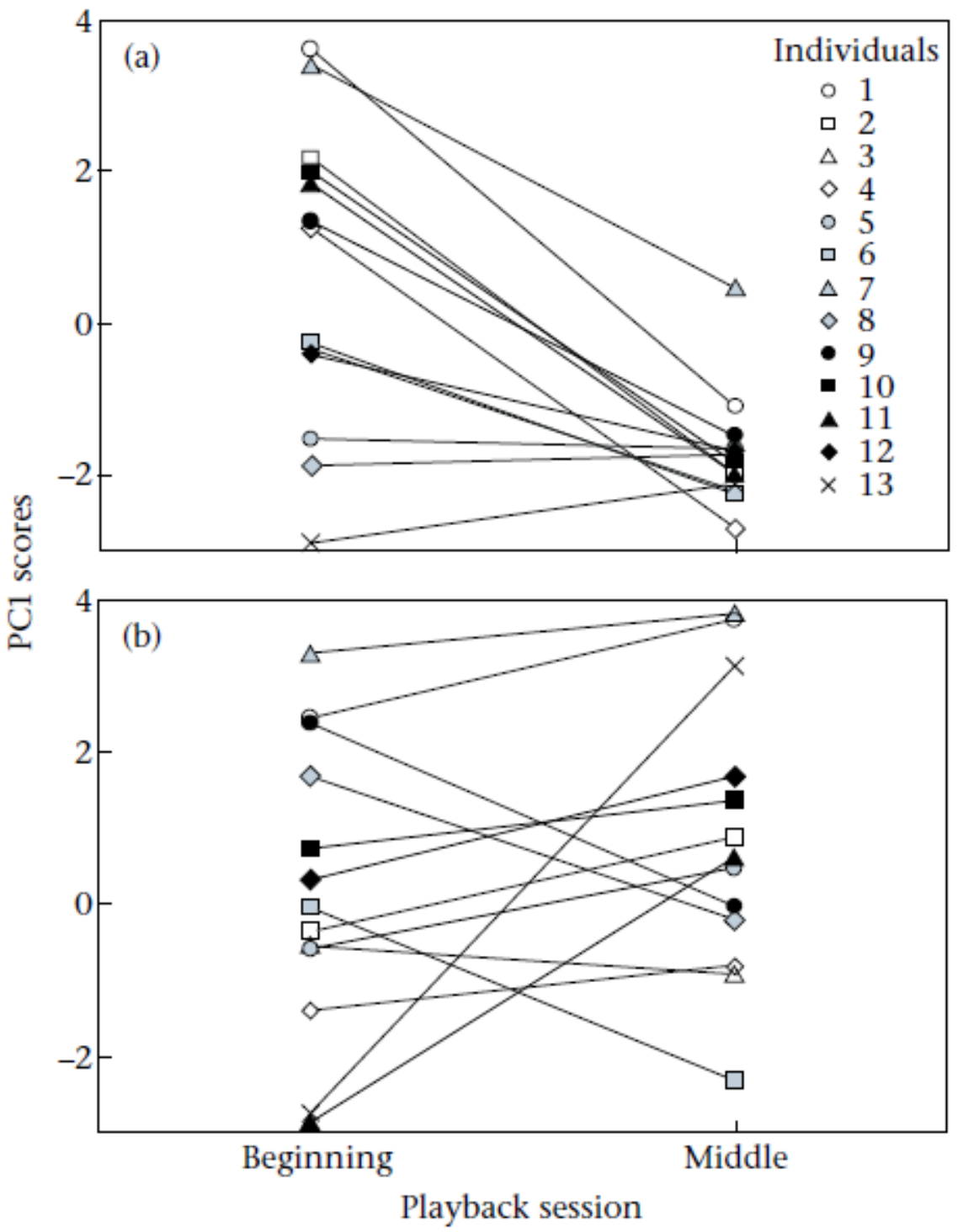

\section{DISCUSSION}

Our goal in the present study was to follow the changes in dear enemy relationships in groups of territorial songbirds tested in the field at different periods of the breeding season. Skylark males showed neighbor- 
stranger (N-S) discrimination, or more exactly familiar-unfamiliar discrimination, consistent with the dear enemy effect in the middle of the breeding season when territory boundaries were well established and stable. When a territorial intrusion was simulated by playback, males indeed reacted more strongly to stranger than to neighbour songs, spending more time moving, approaching closer to the loudspeaker and after a shorter latency, and producing more calls. Numerous other bird species also show such discrimination (Falls \& McNicholl 1979; Brindley 1991; Molles \& Vehrencamp 2001; Lovell \& Lein 2004; Skierczynski et al. 2007), but very few have a repertoire as large as that of skylarks. In oscines, vocal N-S discrimination may be hindered by large song repertoire size (Kroodsma 1976; Godard 1993). Thus, our results do not fit with the 'repertoire constraint' hypothesis (Krebs \& Kroodsma 1980; Falls 1982), which suggests that the task of memorizing a repertoire becomes more difficult as the size of the repertoire increases.

We showed also that a different pattern is obtained at other periods of the breeding season, and that neighbours do not seem to be considered as dear enemies throughout the season. Hence, territory owners did not respond differently to neighbour and stranger songs at the beginning and at the end of the season. Furthermore, although we could not test the same birds throughout the season, our results show that the responses elicited by neighbour songs were more aggressive at the beginning and at the end of the season compared to the middle, whereas the responses elicited by stranger songs did not vary across the season.

Changes in dear enemy relationships observed through the breeding season, between the period of territory settlement and pair formation and the period just after the hatching of the first clutch, could be explained by an increasing familiarity between birds (Ydenberg et al. 1988; Getty 1989). Just after their arrival in the breeding area, individuals are unfamiliar with each other's songs or, as skylarks' site fidelity from year to year is strong (Jenny 1990), have not heard each other's songs for at least several months. They thus may not be able to discriminate neighbours from strangers on an acoustic basis. Over time, within a given location, neighbours have many occasions to hear and to become familiar with each other's songs. They may thus learn (or familiarize themselves again with, if they returned to the same site) the acoustic cues necessary for identifying the members of their group. Such a 'group signature' exists in the neighbour songs of this species, as found in a previous study: several sequences of syllables are shared by neighbouring birds and are used by birds for N-S discrimination (Briefer et al. 2008). Once this signature is learned, males should thus be able to make an accurate N-S discrimination and to show less aggression towards their neighbours. However, the loss of dear enemy relationships at the end of the breeding season cannot be explained by a loss of familiarity with neighbour songs.

Observed changes in dear enemy relationships could also be linked more generally to a habituation process. Habituation is a learning process leading to a decrease in response to a repeated stimulus and has been proposed as a mechanism responsible for the dear enemy effect (Brooks \& Falls 1975; Peeke 1984; Petrinovich 1984; Owen \& Perrill 1998; Bee \& Gerhardt 2001a, b). Residents may habituate to the different communication signals of their neighbours by being repeatedly exposed to these signals across shared territorial boundaries. For instance, skylarks have been shown to reduce their aggressive response after a repeated exposure to the same territorial song (Aubin 1982). However, in our study, the recovery of an aggressive response to the neighbour song at the end of the breeding season indicates that the process underlying reduced aggression between neighbouring male skylarks cannot be habituation alone.

The changes that we observed could also be correlated with modifications of female receptiveness. The threat that an intruder poses to a resident may be to invade part of its territory, or to engage in extrapair copulation with its mate (Temeles 1994). In skylarks, the extrapair copulation rate is high (20\% of extrapair offspring, Hutchinson \& Griffith 2008) and male skylarks are known to use a 'mate-guarding' 
strategy to reduce this rate (Donald 2004). If its female is sexually receptive, a resident may indeed be more likely to be cuckolded and may thus increase its attention and aggression towards its neighbours to prevent extrapair copulations. Female receptiveness is high during the period immediately preceding nest building and egg laying. Our first playback session was conducted before the first nest was built, and our second and third playback sessions were conducted just after the hatching of the first and second clutch, respectively. It is likely that the subjects' females were in a similar sexual state during these last two playback sessions but we observed a difference in the subjects' responses to neighbour songs. Thus, this hypothesis cannot explain all of our results.

Lastly, the observed changes in dear enemy relationships in the skylark could also be explained in the light of changing ecological conditions related to the progression of the breeding behaviour, associated with the relative threat hypothesis proposed by Temeles (1994). During territory settlement and pair formation, territorial boundaries are in constant flux and pairs are not stable. Thus, neighbours and strangers, as potential usurpers of their territory or mate, constitute a similar threat for the residents. Individuals may discriminate between these two categories of intruders but treat them equally aggressively as they both present a risk. During the breeding season, territory borders become less disputed until the time they become well established and pairs start to lay eggs. After the hatching of the first clutch, the neighbours no longer represent any real threat for territory owners. At this time, treating neighbours as dear enemies and achieving stable relationships allow males to invest in territory defence only against more threatening individuals, that is, unfamiliar individuals and floaters. In June, at the end of the breeding season, young birds from the first clutch leave the nests at 1 week, learn to fly at 2 weeks and are aggressively expelled from their natal territory by their parents at 1 month (Delius 1963; Donald 2004). The continuous crossing of the established boundaries by young birds or by parents trying to feed their young in neighbouring territories (Delius 1963) may lower the threshold of the resident's reactivity towards territory intrusion by neighbours and thus destabilize the relationships between adults. The signification of the 'group signature' is thus modified according to the relative threat presented by the neighbours from a meaning of 'dear enemies' to 'nontrustable familiars'. Temporary changes in the social situation seem to be disruptive to the dear enemy effect, which appears to be flexible or 'plastic' rather than a fixed pattern characteristic of the relationship between neighbours (Leiser 2003).

Nevertheless, the explanations according to the four sets of hypotheses are not mutually exclusive. At the very beginning of the season, it is most probable that residents will react with the same intensity to all categories of intruders because they are not familiar with their neighbours, because of their female's high sexual receptiveness, and/or because the territory boundaries are not well established. After a period of learning and memorization of cues necessary for identifying their neighbours, however, residents may distinguish neighbours from strangers and establish dear enemy relationships. Such a learning period might be short if one assumes that skylarks have comparable memorization capacities as hooded warblers, Wilsonia citrina, which remember their neighbours' songs from one year to the next (Godard 1991). At the end of the season, the numerous crossing of the territory boundaries by young birds or by their parents may lower the threshold of territorial response. As a consequence, it is likely that residents then discriminate between intruders, but react strongly to any kind of intruders including neighbours.

To conclude, we have shown that neighbours are not dear enemies throughout the breeding season. In our study, the dear enemy effect seemed to be absent during important flux in territorial boundaries. Thus, in territorial songbirds, accepting neighbours as dear enemies is a conditional strategy that is established over time, as boundaries become more secure and neighbours more familiar, and that can be broken up by changes in the social situation leading to boundary instabilities. 


\section{Acknowledgments}

This study was supported by the CNRS and the University of Paris 11. E.B. is funded by a grant from the French Minister of Research and Technology. We thank Peter Narins for comments and English improvement. We are grateful to the anonymous referees for comments and suggestions.

\section{References}

Aubin, T. 1981. Etude expérimentale du chant territorial de l'alouette des champs (Alauda arvensis L.). Caractéristiques physiques, valeur sémantique et spécificité. Ph.D. thesis, University of Besançon, Nancy 1, Strasbourg.

Aubin, T. 1982. Habituation au chant territorial chez l'alouette des champs (Alauda arvensis L.); rôle de la diversité et de la monotonie. Biology of Behaviour, 7, 353-362.

Axelrod, R. \& Hamilton, W. D. 1981. The evolution of cooperation. Science, 211, 1390-1396. doi:10.1126/science.7466396.

Bee, M. A. 2003. A test of the 'dear-enemy effect' in the strawberry dart-poison frog (Dendrobates pumilio). Behavioral Ecology and Sociobiology, 54, 601-610. doi:10.1007/s00265-003-0657-5.

Bee, M. A. \& Gerhardt, H. C. 2001a. Neighbour-stranger discrimination by territorial male bullfrogs (Rana catesbeiana): I. Acoustic basis. Animal Behaviour, 62, 1129e1140. doi:10.1006/anbe.2001.1851.

Bee,M. A. \& Gerhardt, H. C. 2001b. Neighbour-stranger discrimination by territorial male bullfrogs (Rana catesbeiana): II. Perceptual basis. Animal Behaviour, 62, 1141-1150. doi:10.1006/anbe.2001.1852.

Briefer, E., Aubin, T., Lehongre, K. \& Rybak, F. 2008. How to identify dear-enemies: the group signature in the complex song of the skylark Alauda arvensis. Journal of Experimental Biology, 211, 317326. doi:10.1242/jeb.013359.

Brindley, E. L. 1991. Response of European robins to playback of song: neighbour recognition and overlapping. Animal Behaviour, 41, 503-512. doi:10.1016/S0003-3472(05)80853-X.

Brooks, R. J. \& Falls, J. B. 1975. Individual recognition by song in white-throated sparrows. I. Discrimination of songs of neighbors and strangers. Canadian Journal of Zoology, 53, 879-888. doi:10.1139/cjz-53-7-879.

Craig, C. 2000. Goldwave V. 5.11. St John's, Newfoundland: Goldwave.

Delius, J. D. 1963. Das Verhalten der Feldlerche. Zeitschrift für Tierpsychologie, 20, 297-348.

Delius, J. D. 1965. A population study of skylarks Alauda arvensis. Ibis, 107, 466-492.

Donald, P. F. 2004. The Skylark. London: T.\&A.D. Poyser.

Dunn, R. \& Messier, S. 1999. Evidence for the opposite of the dear enemy phenomenon in termites. Journal of Insect Behavior, 12, 461-464. doi:10.1023/A:1020958505815.

Falls, J. B. 1982. Individual recognition by sound in birds. In: Acoustic Communication in Birds II (Ed. by D. E. Kroodsma \& E. H. Miller), pp. 237-274. New York: Academic Press.

Falls, J. B. \& McNicholl, M. K. 1979. Neighbour-stranger discrimination by song in male blue grouse. Canadian Journal of Zoology, 57, 457-462. doi:10.1139/cjz-57-2-457.

Fisher, J. 1954. Evolution and bird sociality. In: Evolution as a Process (Ed. by J. Huxley, A. C. Hardy \& E. B. Ford), pp. 71-83. London: Allen \& Unwin.

Getty, T. 1989. Are dear enemies in a war of attrition? Animal Behaviour, 37, 337-339. doi:10.1016/00033472(89)90125-5.

Godard,R. 1991. Long-term memory of individual neighbours in a migratory songbird. Nature, 350, 228229. doi:10.1038/350228a0.

Godard, R. 1993. Tit for tat among neighboring hooded warblers. Behavioral Ecology and Sociobiology, 33, 45-50. doi:10.1007/BF00164345. 
Husak, J. F. \& Fox, S. F. 2003. Adult male collared lizards, Crotaphytus collaris, increase aggression towards displaced neighbours. Animal Behaviour, 65, 391-396. doi:10.1006/anbe.2003.2058.

Hutchinson, J. M. C. \& Griffith, S. C. 2008. Extra-pair paternity in the skylark Alauda arvensis. Ibis, 150, 90-97. doi:10.1111/j.1474-919X.2007.00744.x.

Hyman, J. 2005. Seasonal variation in response to neighbors and strangers by a territorial songbird. Ethology, 111, 951-961. doi:10.1111/j.1439-0310.2005.01104.x.

Hyman, J. \& Hughes, M. 2006. Territory owners discriminate between aggressive and nonaggressive neighbours. Animal Behaviour, 72, 209-215. doi:10.1016/j.anbehav.2006.01.007.

Jenny, M. 1990. Populations dynamik der Feldlerche Alauda arvensis in einer intensive genutzten Agrarlandschaft des schweizerischen Mittellandes. Ornithologische Beobachter, 87, 153-163.

Krebs, J. R. \& Kroodsma, D. E. 1980. Repertoire and geographical variation in bird song. In: Advances in the Study of Behavior II (Ed. by J. S. Rosenblatt, R. A. Hinde, C. Beer \& M. C. Busnel), pp. 134177. New York: Academic Press.

Kroodsma, D. E. 1976. The effect of large song repertoires on neighbor 'recognition' in male song sparrows. Condor, 78, 97-99.

Lachish, S. \& Goldizen, A. W. 2004. Responses to neighbours and non-neighbours in the buff-banded rail (Gallirallus philippensis): no dear-enemy relationships. Australian Journal of Zoology, 52, 369378. doi:10.1071/ZO03029.

Lange, H. 1951. On the song-length of the skylark (Alauda arvensis L.). Dansk Ornithologisk Forenings Tidsskrift, 45, 34-43.

Leiser, J. K. 2003. When are neighbours 'dear enemies' and when are they not? The responses of territorial male variegated pupfish, Cyprinodon variegatus, to neighbours, strangers and heterospecifics. Animal Behaviour, 65, 453-462. doi:10.1006/anbe.2003.2087.

Leiser, J. K. \& Itzkowitz, M. 1999. The benefit of the dear enemy recognition in three-contender convict cichlid (Cichlasoma nigrofasciatum) contests. Behaviour, 136, 983e1003. doi:10.1163/156853999501685.

Lovell, S. F. \& Lein, M. R. 2004. Neighbor-stranger discrimination by song in a suboscine bird, the alder flycatcher, Empidonax alnorum. Behavioral Ecology, 15, 799-804. doi:10.1093/beheco/arh082.

McGregor, P. K. 1992. Quantifying responses to playback: one, many, or composite multivariate measures. In: Playback and Studies of Animal Communication (Ed. by P. K. McGregor), pp. 7996. New York: Plenum.

McGregor, P. K., Catchpole, C. K. \& Dabelsteen, T. 1992. Design of playback experiments: the Thornbridge Hall NATO ARW consensus. In: Playback and Studies of Animal Communication (Ed. by P. K. McGregor), pp. 1-9. New York: Plenum.

Molles, L. E. \& Vehrencamp, S. L. 2001. Songbird cheaters pay a retaliation cost: evidence for auditory conventional signals. Proceedings of the Royal Society of London, Series B, 268, 2013-2019. doi:10.1098/rspb.2001.1757.

Morimura, S. S., Minai, M., Yokoyama, M., Hirota, T., Satoh, T. \& Obara, Y. 2003. Encounter-induced hostility to neighbors in the ant Pristomyrmex pungens. Behavioral Ecology, 14, 713-718. doi:10.1093/beheco/arg057.

Müller, C. A. \& Manser, M. B. 2007. 'Nasty neighbours' rather than 'dear-enemies' in a social carnivore. Proceedings of the Royal Society of London, Series B, 274, 959-965. doi:10.1098/rspb.2006.0222.

Naguib, M.\& Todt, D. 1998. Recognition of neighbor's song in a species with large and complex song repertoires: the thrush nightingale. Journal of Avian Biology, 29, 155-160.

Olendorf, R., Getty, T., Scribner, K. \& Robinson, S. K. 2003. Male red-winged blackbirds distrust unreliable and sexually attractive neighbours. Proceedings of the Royal Society of London, Series B, 271, 1033-1038. doi:10.1098/rspb.2004.2687. 
Owen, P. C. \& Perrill, S. A. 1998. Habituation in the green frog, Rana clamitans. Behavioral Ecology and Sociobiology, 44, 209-213. doi:10.1007/S002650050533.

Peeke, H. V. S. 1984. Habituation and the maintenance of territorial boundaries. In: Habituation, Sensitization, and Behavior (Ed. By H. V. S. Peeke \& L. Petrinovich), pp. 393-421. New York: Academic Press.

Petrinovich, L. 1984. A two-factor dual-process theory of habituation and sensitization. In: Habituation, Sensitization and Behavior (Ed. by H. V. S. Peeke \& L. Petrinovich), pp. 17e55. New York: Academic Press.

Pfennig, D. W. \& Reeve, H. K. 1989. Neighbour recognition and context-dependent aggression in a solitary wasp, Sphecius speciosus (Hymenoptera: Sphecidae). Ethology, 80, 1-18.

Randall, J. A. 1984. Territorial defence and advertisement by foot-drumming in bannertail kangaroo rats (Dipodomys spectabilis) at high and low population densities. Behavioral Ecology and Sociobiology, 16, 11-20. doi:10.1007/BF00293099.

Skierczynski, M., Czarnecka, K. M. \& Osiejuk, T. S. 2007. Neighbour-stranger discrimination in territorial ortolan bunting Emberiza hortulana males. Journal of Avian Biology, 38, 415-420. doi:10.1111/j.0908-8857.2007.04123.x.

Specht, R. 2004. Avisoft SASLab pro v4.31. Berlin: Avisoft. StatSoft, Inc 2001. Statistica v6.0. for Windows (Computer Program Manual). Tulsa, Oklahoma: StatSoft Inc.

Stoddard, P. K., Beecher, M. D., Horning, C. L. \& Willis, M. 1990. Strong neighbor-stranger discrimination in song sparrows. Condor, 92, 1051-1056.

Stoddard, P. K., Beecher, M. D., Horning, C. L. \& Campbell, S. E. 1991. Recognition of individual neighbors by song in the song sparrow, a bird with song repertoires. Behavioral Ecology and Sociobiology, 29, 211-215. doi:10.1007/BF00166403.

Temeles, E. J. 1990. Northern harriers on feeding territories respond more aggressively to neighbours than to floaters. Behavioral Ecology and Sociobiology, 26, 57-63. doi:10.1007/BF00174025.

Temeles, E. J. 1994. The role of neighbours in territorial systems: when are they 'dear enemies'? Animal Behaviour, 47, 339-350. doi:10.1006/anbe.1994.1047.

Trivers, R. 1971. The evolution of reciprocal altruism. Quarterly Review of Biology, 46, 35-57.

Ydenberg, R. C., Giraldeau, L. A. \& Falls, J. B. 1988. Neighbours, strangers, and the asymmetric war of attrition. Animal Behaviour, 36, 343-347. doi:10.1016/S0003-3472(88)80004-6. 